Contract No. and Disclaimer:

This manuscript has been authored by Savannah River Nuclear Solutions, LLC under Contract No. DE-AC09-08SR22470 with the U.S. Department of Energy. The United States Government retains and the publisher, by accepting this article for publication, acknowledges that the United States Government retains a non-exclusive, paid-up, irrevocable, worldwide license to publish or reproduce the published form of this work, or allow others to do so, for United States Government purposes. 


\section{COMPARISON OF EXPERIMENTAL RESULTS TO CFD MODELS FOR BLENDING IN A TANK USING DUAL OPPOSING JETS}

Robert A. Leishear

Savannah River National Laboratory

Aiken, S. C., USA

\author{
Michael R. Poirier \\ Savannah River National \\ Laboratory \\ Aiken, S. C., USA
}

\author{
Si Y. Lee \\ Savannah River National Laboratory \\ Aiken, S. C., USA
}

\begin{abstract}
Research has been completed in a pilot scale, eight foot diameter tank to investigate blending, using a pump with dual opposing jets. The jets re-circulate fluids in the tank to promote blending when fluids are added to the tank. Different jet diameters and different horizontal and vertical orientations of the jets were investigated. In all, eighty five tests were performed both in a tank without internal obstructions and a tank with vertical obstructions similar to a tube bank in a heat exchanger. These obstructions provided scale models of several miles of two inch diameter, serpentine, vertical cooling coils below the liquid surface for a full scale, 1.3 million gallon, liquid radioactive waste storage tank. Two types of tests were performed. One type of test used a tracer fluid, which was homogeneously blended into solution. Data were statistically evaluated to determine blending times for solutions of different density and viscosity, and the blending times were successfully compared to computational fluid dynamics (CFD) models. The other type of test blended solutions of different viscosity. For example, in one test a half tank of water was added to a half tank of a more viscous, concentrated salt solution. In this case, the fluid mechanics of the blending process was noted to significantly change due to stratification of fluids. CFD models for stratification were not investigated. This paper is the fourth in a series of papers
\end{abstract}

resulting from this research (Leishear, et.al. [1- 4]), and this paper documents final test results, statistical analysis of the data, a comparison of experimental results to CFD models, and scale-up of the results to a full scale tank.

\section{INTRODUCTION}

At the Savannah River Site (SRS), S. C., the Salt Disposition Integration (SDI) portfolio of projects provides the infrastructure within existing Liquid Waste facilities to support the startup and long term operation of the Salt Waste Processing Facility (SWPF), which will separate radioactive salts from bulk salt solution mixtures. Within SDI, the Blend and Feed Project will equip several of forty-nine existing waste tanks in the SRS Tank Farms to serve as Blend Tanks where $300,000-800,000$ gallons of salt solution will be blended in 1.3 million gallon Blend Tanks and qualified for use as feedstock for SWPF. Blending requires miscible salt solutions from multiple source tanks per batch to be well mixed without disturbing settled sludge solids that may be present in a Blend Tank. Various metals and radionuclides settle to the tank bottom to form a viscous mixture, referred to as sludge (Leishear. et al. [2]). Disturbing solids may be problematic both from an SWPF feed quality perspective as well as from a process safety perspective where hydrogen release from the sludge is potentially a flammability concern.

This manuscript has been authored by Savannah River Nuclear Solutions, LLC under Contract No. DE-AC09-08SR22470 with the U.S. Department of Energy. The United States Government retains and publisher, by accepting this article for publication, acknowledges that the United States Government retains a non-exclusive, paid-up, irrevocable, worldwide license to publish or reproduce the published form of this work, or allow others to do so, for United States Government Purposes

To develop the necessary technical basis for the design and operation of the blending equipment, Savannah River National Laboratory (SRNL) completed scaled blending pump tests and computational fluid dynamics (CFD) modeling. A 94 inch diameter pilot-scale blending tank, including tank internals such as the blending pump, removable cooling coils, 
and center column were used in this research. The test tank represents a 1/10.85 scaled version of an 85 foot diameter nuclear waste tank that may be typical of Blend Tanks used in SDI. SRNL blending tests investigated various fixed position, non-rotating, dual nozzle pump designs, including a blending pump model provided by the blend pump vendor, Curtiss Wright $(\mathrm{CW})$.

Primary research goals were to assess blending times and to evaluate incipient sludge disturbance for waste tanks. Incipient sludge disturbance was defined by the operating contractor, Savannah River Remediation, LLC (SRR) and SRNL as minor blending of settled sludge solids from the tank bottom into suspension due to blending pump operation, where the sludge depth was shown to remain constant. To experimentally model the sludge layer, a very thin, pourable, sludge simulant was conservatively used for all testing. To experimentally model the liquid, supernate layer above the sludge in waste tanks, two salt solution simulants were used, which provided a bounding range of supernate properties. One solution was water $\left(\mathrm{H}_{2} \mathrm{O}+\mathrm{NaOH}: p H=11\right)$, and the other was a more viscous salt solution.

The research performed and data obtained significantly advances the understanding of fluid mechanics, mixing theory, and CFD modeling for nuclear waste tanks by benchmarking CFD results to actual experimental data. To do so, this research bridges the gap between CFD models and mixing in tanks by demonstrating that significant experimental variations of blending times occur, which are not addressed by CFD modeling methods. That is, CFD methods provide an engineering approximation of blending times, but actual mixing processes are far more chaotic and variable than CFD models demonstrate. Correction factors for calculated CFD blending times were determined in this research to overcome this deficiency in CFD modeling for blending processes.

\section{NOMENCLATURE}

C correlation factor

$C_{f} \quad$ CFD blending time correction factor

$C F D$ computational fluid dynamics

$C W$ Curtiss Wright, Inc.

$D \quad$ nozzle diameter, feet

pH - log of the Hydronium ion concentration

$r \quad$ radial position, feet

$S D I \quad$ Salt Disposition Integration Project

SRR Savannah River Remediation, LLC

SRS Savannah River Site

SWPF Salt Waste Processing Facility

SRNL Savannah River National Laboratory

$t \quad$ blending time, minutes

$T \quad$ tank diameter, feet

$U(x, r) \quad$ velocity in a jet, feet/second

UoD pump design parameter, feet ${ }^{2} /$ second

Uo nozzle velocity, feet/second
$V F D \quad$ variable frequency drive

$x \quad$ axial position, feet

$\sigma \quad$ standard deviation

\section{PILOT SCALE TEST EQUIPMENT DESCRIPTION}

A full description of the full scale and pilot scale equipment is available (Leishear, et al. [1 and 3]). The pilot scale tank with removable cooling coil models installed is shown in Figure 1. Although several pump model designs were used during testing, Figure 2 shows a drawing of the final pump model, referred to as the $\mathrm{CW}$ design. Figure 3 shows that model installed in the pilot scale tank without coils installed. For comparison of the pump model to the actual pump design, Fig. 4 is provided. For the full size pump, flow is drawn up into the bottom of the pump through a screen, into the impeller, and out through the two opposing nozzles. To describe flow through the pilot scale nozzles, a system schematic is required.

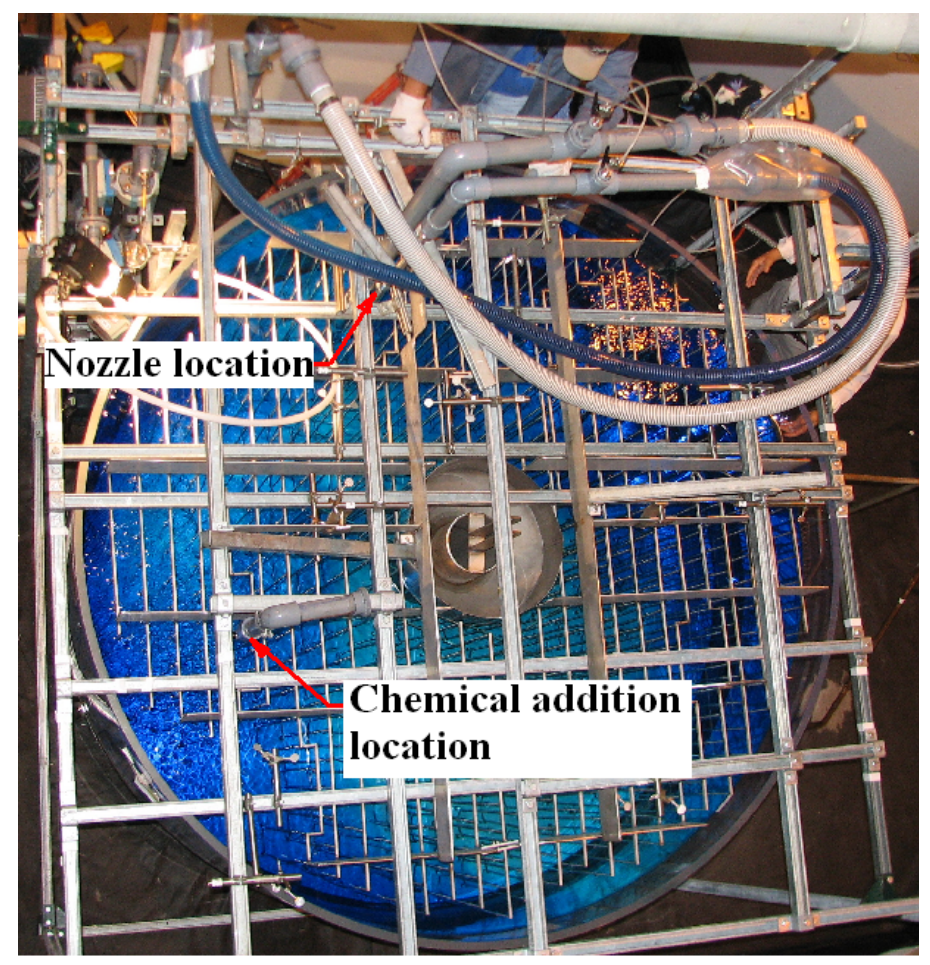

Figure 1: Pilot Scale Tank With Cooling Coil Models Installed

\section{PILOT SCALE TESTING AND SYSTEM SCHEMATIC}

To perform tests, equipment and instrumentation was installed as shown in the schematic of Fig. 5. A re-circulating pump provided flow through the two nozzles to blend the tank contents. The pump speed was controlled using a variable frequency drive (VFD) to provide different flow rates to vary $U o D$, which is a design parameter obtained by multiplying the nozzle diameter, $D$ times the nozzle velocity $U o$. Turbidity probes were used to measure concentrations of particles in 
suspension during sludge disturbance tests, and $p H$ probes were used to measure concentrations during blending tests.

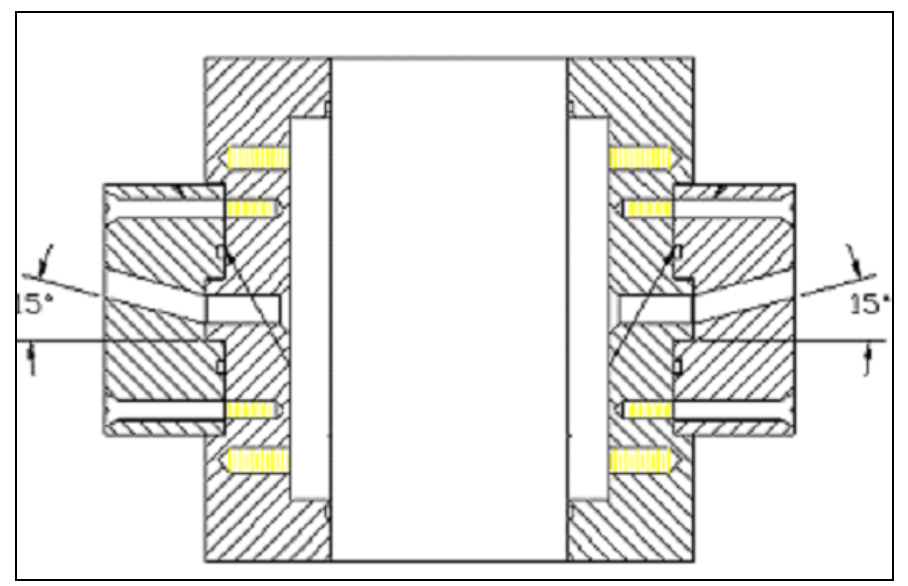

Figure 2: Pump Model

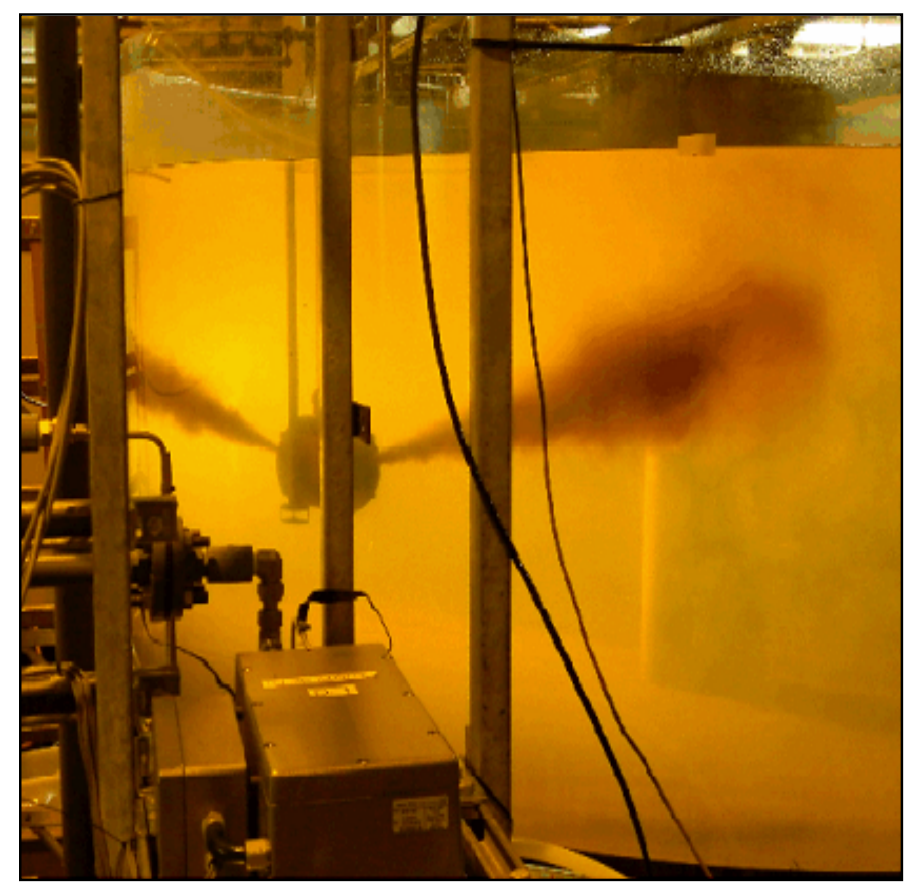

Figure 3: Pump Model installed in the Pilot Scale Tank

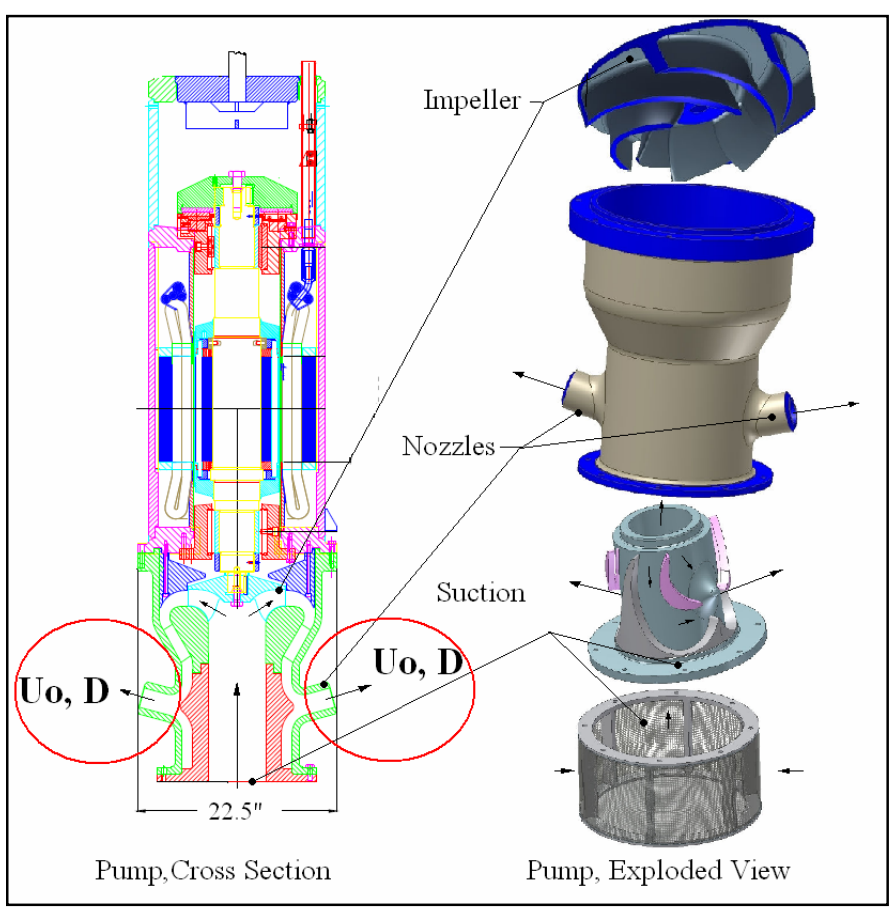

Figure 4: Full Scale Pump Design (CW)

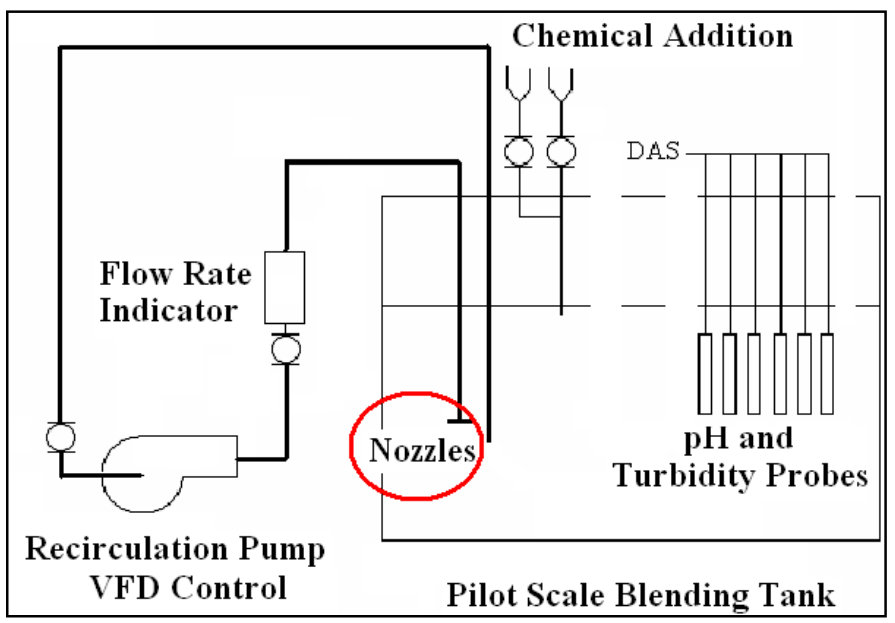

Figure 5: Test Schematic

\section{BLENDING AND UoD}

Consistent with Grenville's work [5 and 6], the quantity, $U o D$, was shown to be the controlling factor for blending, where $U o$ equals the velocity for each nozzle and $D$ equals the diameter of each nozzle. A discussion is available for application of published theory to this research and for the relationships between $U o D$ and blending (Leishear, et.al. [1]). This paper focuses on the relationship between experimental results and CFD models.

To quantify blending performance, blending times were determined using a commonly used $95 \%$ blending criteria, 
defined by Paul, et al. [7]). Tracer quantities of acids and bases were added to the pilot scale tank at a common location for each test, and $p H$ was measured at multiple locations as the acid or base was blended into solution. The Hydronium ion concentrations $\left[\mathrm{H}_{3} \mathrm{O}^{+}\right]$were calculated from $\mathrm{pH}$ measurements and normalized to establish mixing times for $95 \%$ mixing (Paul, et al [7]). The 95\% mixing criterion is a generally accepted criterion which defines the time following the addition of a tracer at which the concentrations throughout the tank are within $\pm 5 \%$ of the bulk concentration. Normalization is a common practice for empirically quantifying mixing using concentration measurements (Paul, et al. [7]). The 95\% mixing time provided blending acceptance criterion. A typical blending test result is shown in Fig. 6. A mixing comparison was also performed to evaluate $p H$ probe use by comparing normalized hydronium ion concentrations to experimentally measured sodium concentrations, where $50 \mathrm{ml}$ samples were obtained near a $p H$ probe during testing, and sodium concentration was measured near that probe within $\pm 10-20 \%$ accuracy. The results are shown in Fig. 7.

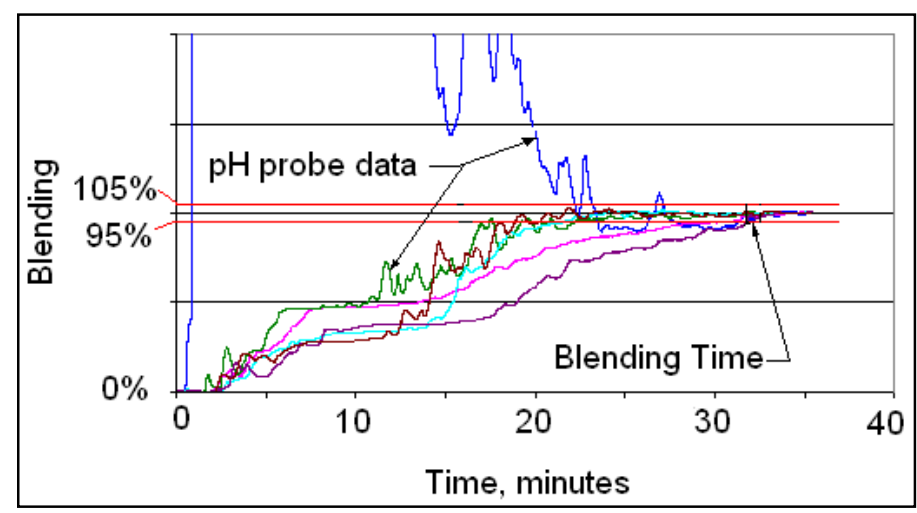

Figure 6: Typical Blending Time Test Result

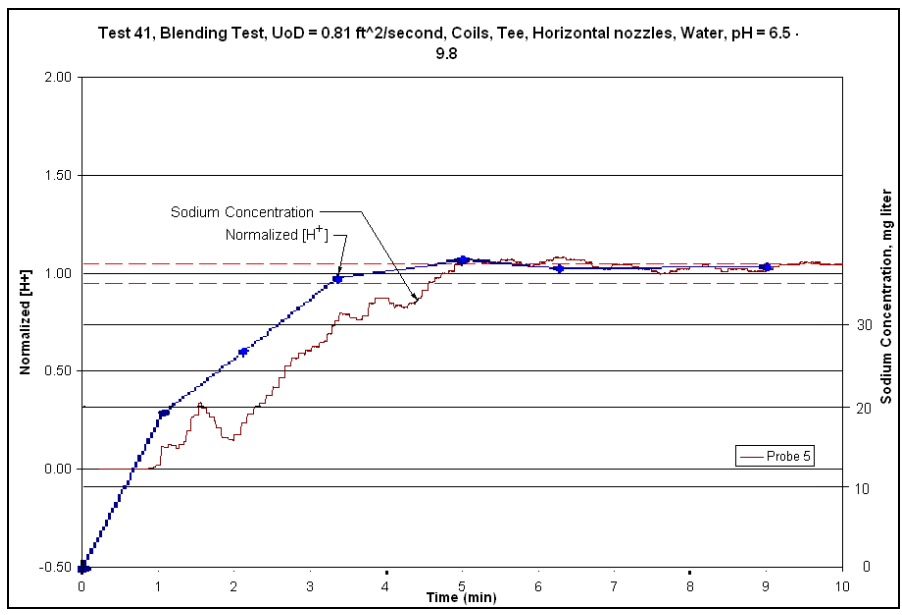

Figure 7: Comparison of Normalized Hydronium Concentrations to Measured Sodium Concentrations

\section{PILOT SCALE RESEARCH REQUIREMENTS}

Research was divided into two phases. Phase 1 tests were performed to provide preliminary design requirements for the blending pump to effectively blend the tank contents. Phase 1 results are summarized in Table 1. Phase 2 tests were performed to confirm those requirements with additional blending tests, and also investigate sludge disturbance requirements for the blending pump. Phase 2 test results are summarized in Table 2 and graphically summarized in Fig. 211 of Annex A.

\section{SUMMARY OF INITIAL, PHASE 1, BLENDING TEST RESULTS AND OBSERVATIONS}

Design parameters were investigated in Phase 1 to establish design recommendations, and the reader is referred to the Phase 1 research (Leishear, et al. [1 and 3] for a supporting discussion of test results. Phase 1 test results are summarized in Fig. 8, where nozzle design, nozzle diameters, and flow rates were varied to change $U o D$. Data were analyzed to establish the following relationships.

1. Pilot scale blending times were significantly affected by cooling coil installation. Blending times in a tank with coils were twice the blending times for a tank without coils, within the recommended range of operation. Below the recommended range of operation the basic fluid mechanics of blending is not understood, and blending times for a tank with coils was as much as seven times the blending time for a tank without coils at pilot scale.

2. Molecular diffusion was very slow when compared to blending times, and consequently had a negligible effect on blending.

3. Pilot scale blending times in a tank with coils varied by more than $100 \%$ for the same nozzle design and $U o D$, but this variation was included in the statistical analysis of the data to provide a conservative blending time estimate.

4. For $p H$ tests, pilot scale blending times were independent of initial and final concentrations of acid or base. This observation validated the equivalence of many different tests, which had different starting and ending $p H$ conditions.

5. A nozzle position parallel to the vertical tank wall was recommended to minimize sludge disturbance at the tank wall.

6. Nozzle position and diameter had minor effects on blending times.

7. Nozzle diameter effects were not investigated outside the range of selected diameters (1-1/2" - 3-5/8" scaled down to 0.138 " and 0.334 " respectively). At smaller diameters, conclusions with respect to $U_{0} D$ and blending times may not be valid.

8. A $95 \%$ blending time criterion was validated for use in test results, and a $99 \%$ blending time could not be 
obtained due to technical limitations of commercial equipment. That is, $99 \%$ bending times may be approximated, since instrumentation is inadequate to effectively measure $99 \%$ blending.

9. $p H$ measurements during testing were acceptable to describe normalized blending times near equilibrium, but were significantly in error during testing due to the buffering effects of carbonates formed in solution.

10. Instrument uncertainties were shown to be negligible with respect to $U o D$. All variances in blend times were shown to be realistic expectations.

11. Visual indications using blue dye additions to the tank instead of acid / base additions indicated much lower blending times than determined by using $p H$ measurements. This observation was consistent with Grenville's observations on this topic [5 and 6].

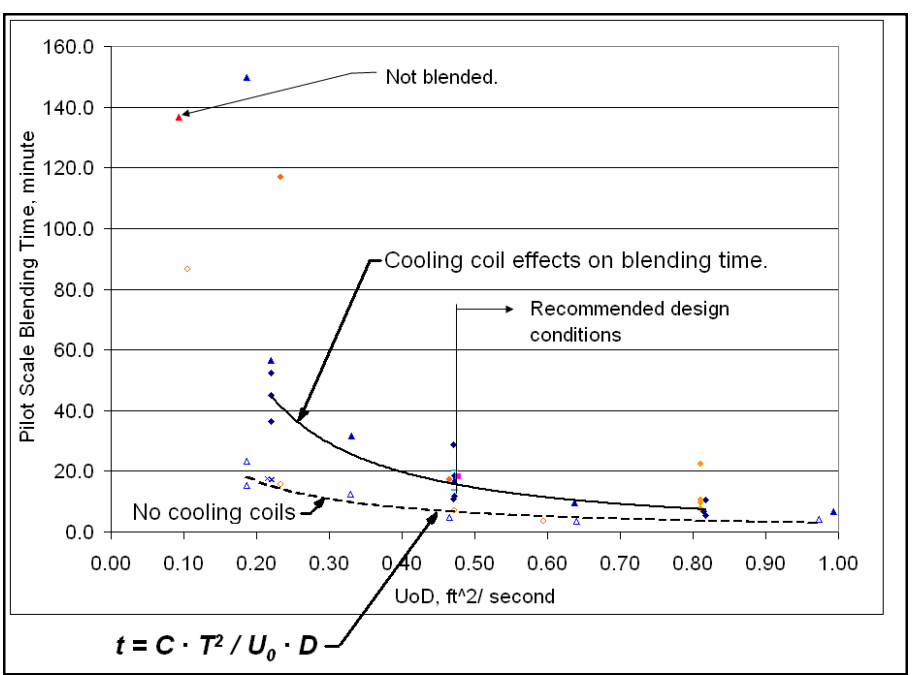

Figure 8: Comparison of Pilot Scale Test Results for a Tank With or Without Cooling Coils

\section{LITERATURE RESULTS}

A literature review was performed to determine the present level of understanding for blending time predictions for comparison to the present research. Dimenna, et al. [8] provided the most recent summary of blending research applicable to nuclear waste storage tanks, but Grenville [5 and 6] provided an excellent summary of blending research for experiments in open tanks up to 1.3 million gallon capacity, which were mixed using a single nozzle jet positioned at a lower corner of the tank and aimed upward toward the fluid surface at the far side of the tank. Also, some work has been completed to compare CFD models to experimental results for single mixing jets (Patwardhan [9] and Rahimi and Parvareh [10]).

\section{Literature Results for CFD Comparisons to Measured Blending Times}

Using standard $\kappa-\varepsilon$ turbulence models, Patwardhan [9] showed that CFD models may be used to provide estimates for blending times, as shown in Fig. 9. His tests in a 1.64 foot diameter tank were performed using a setup similar to that shown in Fig. 10. The variance between CFD estimates and experiment were not fully investigated, but the variance between CFD models and experimental results were considered in this research.
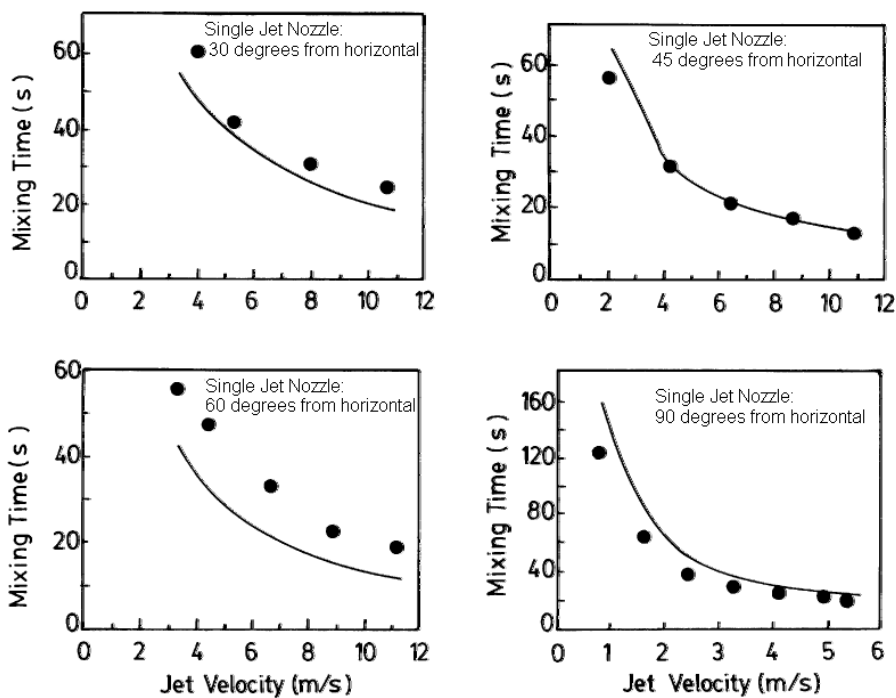

Figure 9: Comparison of CFD Models to Experiment for Single Nozzle Tests (Patwardhan [9])

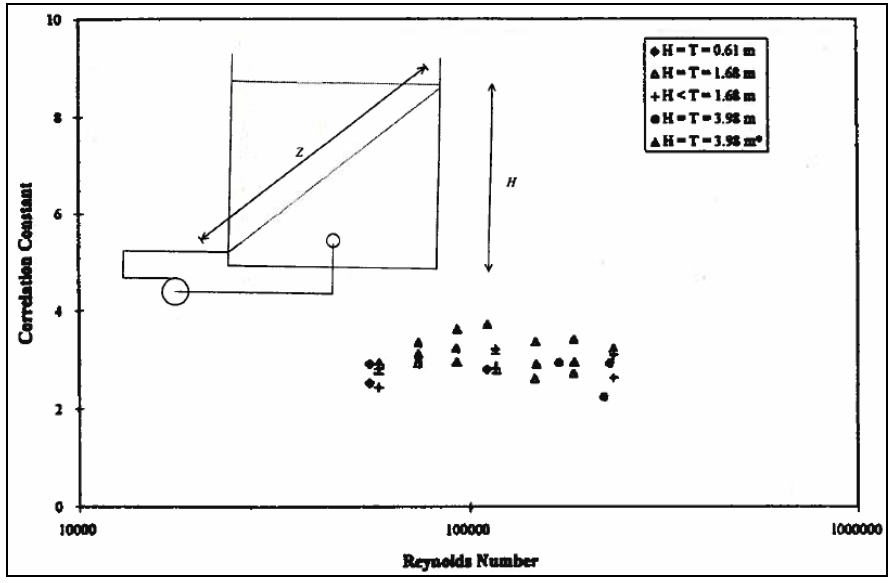

Figure 10: Blending Test Results for a Single Nozzle (Grenville [5 and 6])

\section{Literature Results for Blending Time Equations}

Grenville [5 and 6] performed a number of experiments in addition to evaluating research from others, using the tank geometry shown in Fig. 10, where $H$ is the height of the fluid, and $Z$ is the path length of the jet. From these data, Grenville expressed the blending time as 


$$
t=\left(C \cdot T^{2}\right) /\left(U_{0} \cdot D\right)=\left(3.00 \cdot T^{2}\right) /(U o \cdot D)
$$

where the blending time, $t$, was expressed in terms of the tank diameter, $T$, an experimentally derived correlation factor, $C$, and $U o D$. His work also summarized the effects of the jet angle to a horizontal plane, where the blending time increases as the jet angle is decreased toward the floor of the tank.

Grenville's data pertinent to this research are summarized in terms of Reynold's number at the nozzle exit. Grenville also noted that the standard deviation $(\sigma)$ for blending times was $11.85 \%$ for the data shown in Fig. 10. This uncertainty and blending time predictions were compared to the current research, even though the number of nozzles, nozzle location, and tank geometry were different. That is, Equation 1 was shown to provide an adequate description of mixing for a tank without coils and dual opposing jets in the range of interest.

\section{Phase 1 Research Conclusions for Blending Times}

For pilot scale testing in a tank without coils performed during Phase 1 research, blending time predictions were similar to Grenville's work for blending of a tank with a single nozzle, where

$$
t=\left(C \cdot T^{2}\right) /\left(U_{0} \cdot D\right)=\left(3.72 \cdot T^{2}\right) /(U o \cdot D)
$$

Inspection of Fig. 8 shows that the experimental data for blending times in a tank without coils may also be considered using a correlation comparable to Grenville's Equation 2. To do so, simply change the value of the correlation factor to $C=$ 3.72 , for values of $U o D$ above $0.33 \mathrm{feet}^{2} /$ second. Below $U o D$ $=0.33 \mathrm{feet}^{2} / \mathrm{second}$, the relationship between blending times and $U o D$ becomes non-linear, where the fluid mechanics of blending apparently change. As flow rates into the tank decrease, the ability of the pump to effectively blend the tank contents decreases until a value of $U o D$ is reached where the tank is not completely blended, as shown in Fig. 11. Alternatively, $U o D$ is non-linear below $0.47 \mathrm{feet}^{2} / \mathrm{second}$ for a tank with coils installed.

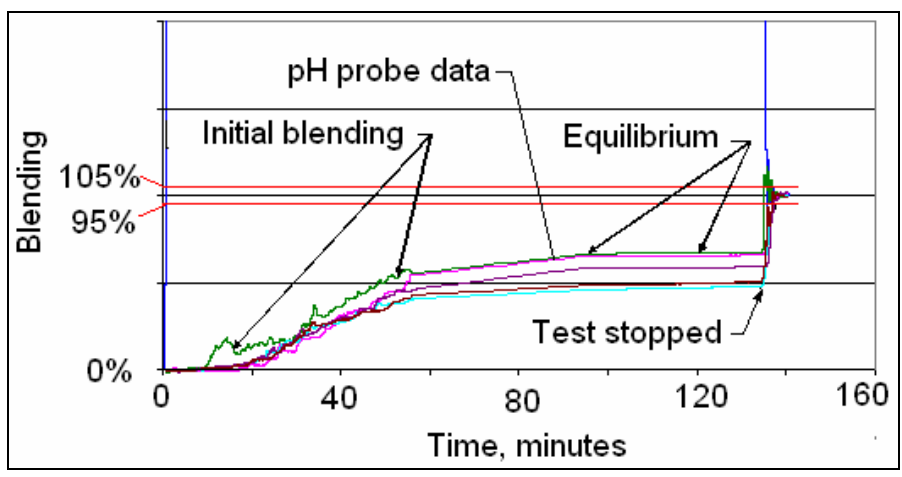

Figure 11: Incomplete Blending

Two conclusions may be gleaned from Fig. 8. First, coils significantly affect the average blending time. Second, significant variation in blending times occurs for similar tests. In short, coils significantly affect not only the average blending time at a given $U o D$ in the pilot scale tank, but also the variation of blend time with respect to the mean changes considerably at any given $U o D$ regardless of coil installation. This variation is not just a mathematical uncertainty, but is a physical phenomenon where the blending time changes significantly for comparable conditions. These observed blending time variations about the mean in a pilot scale tank with coils are assumed to also occur at full scale.

\section{Scale-up of Pilot Scale Blending Time Variations}

To consider blending time variations at full scale, the velocity is assumed to be equivalent throughout the tank at either full or pilot scale, and blending time variations are then assumed to be equivalent at either scale. Some explanation is required to clarify and justify this statement

Single phase liquid blending can be scaled on the basis of equivalent fluid motion (Rautzen, et al. [11]). The fluid motion in the tanks comes from the turbulent jet produced by the mixer pumps. Equation 3describes the jet velocity as a function of position

$$
U(x, r)=\left(6 U_{0} D / x\right) \exp \left(-40(r / x)^{2}\right)
$$

where $x$ is the longitudinal distance, $r$ is the radial distance from the jet centerline, $U(x, r)$ is the velocity at a point in the jet (Davies [12]). If the pilot-scale tank is geometrically scaled, $D / x$ and $r / x$ will be the same in the pilot-scale tank and the full-scale tank. Therefore, if the pilot-scale tank and the full-scale tank have the same nozzle velocity, they will have the same jet velocity at equivalent locations in the tank. Initially velocities throughout the tank were also assumed to be the same at both scale, and according to CFD modeling, this assumption was reasonably accurate for a tank with coils, and for a tank without coils velocities on the tank floor were slightly higher ( $0.42 \mathrm{feet} / \mathrm{second}$ at full scale compared to 0.36 feet/second at pilot scale) for CFD models than predicted by linear scaling of pilot scale experimental results.

Since velocities in the tank scale up nearly linearly, and blending times theoretically scale-up linearly, the variability of blend time about the mean at pilot scale is assumed to be applicable to blending times at full scale. A value for the blending time variability was determined in this Phase 2 pilot scale research for a tank with coils either installed or uninstalled, which was then applied to full scale CFD results. This variability was not applied to blending time estimates obtained from Equation 2.

\section{PHASE 2, BLENDING TEST RESULTS AND OBSERVATIONS}

Phase 2 blending tests focused on final design requirements for the blending pump. Basically, Table 2 
summarizes the design parameters and test groupings, which were investigated and statistically analyzed in Phase 2 research. All of the pertinent test results from both Phase 1 and Phase 2 are displayed in Fig. 21, and the data in this figure were used to compare the effects of various parameters on blending times, where the average value of each set of tests is shown as a straight line for all of the probes in a related group of tests. Accordingly, the effects of any test parameter can be investigated, such as $U o D$, cooling coil installation, or type of fluid.

Additionally, some data sets were shown to be more influential on recommendations. In particular, those data sets described the variability of average experimental blending times with respect to CFD models, and provided blending times at the operating conditions where sludge disturbance was observed for testing with and without cooling coil models installed.

Significant conclusions from data analysis are that:

1. A negligible blending improvement is noted when nozzle designs were changed from a tee (Fig. 12) to the $\mathrm{CW}$ design (compare tests 61-63 to 64-68). This observation further demonstrated that $U o D$ is the primary factor with respect to pump design, rather than specific pump design details.

2. Changes in kinematic viscosity have a negligible effect on blending when coils are installed (compare tests 78-81 to tests 48-51).

3. From analysis of Fig. 8 and Fig. 21, the recommended minimum pilot scale, pump design requirements are $U o D>0.33 \mathrm{feet}^{2} / \mathrm{sec}$ for a tank without coils, and $U o D>0.47 \mathrm{feet}^{2} / \mathrm{sec}$ for a tank with coils. Although blending can probably be performed at lower $U o D$ 's than recommended, there was insufficient available data at lower $U o D$ to extrapolate test results to full scale from test results and accompanying analysis.

4. Consistent with Phase 1 observations, the initial and final testing $p H$ had a negligible effect on blending times. For example, comparable blend times (11.0 and 11.9 minutes) were observed when the $p H$ test range varied by either 5.86 or 1.52 (Tests 12 and 13 respectively).

5. A review of test data concluded that blending times varied considerably for the same design conditions. For example, Tests 52 and 58 had similar test conditions, i.e., $p H$ conditions (7.3-10.4 and 7.4-10.8), operating temperatures $\left(70^{\circ} \mathrm{F}\right.$ and $\left.71^{\circ} \mathrm{F}\right)$, fluids, procedures, and $U o D$. However, blending times varied by more than a factor of 2.3, when maximum blending times were 18.25 and 7.94 minutes, respectively. This example is characteristic of blending time results, where there was a large variation in blending time for apparently identical conditions.

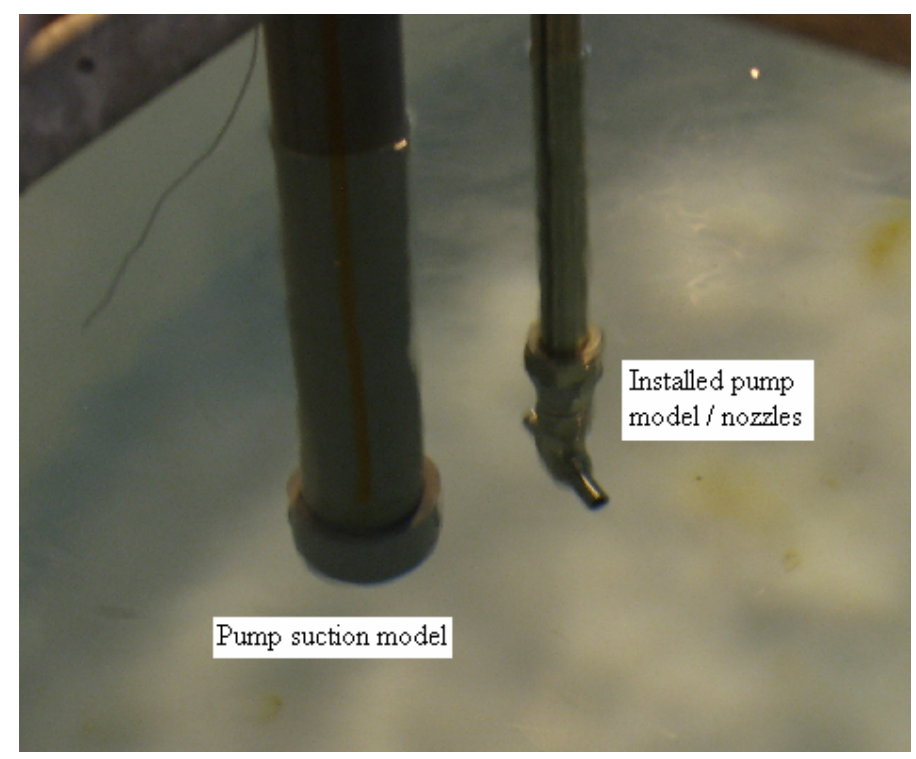

Figure 12: Optional “Tee” Nozzle Designs

\section{SLUDGE DISTURBANCE AND CFD MODELS}

Minimal sludge disturbance was permitted when small wisps of sludge were blended into solution (Fig. 13), but the sludge level remained constant over a 24 hour period. Turbidity probes were also used to measure negligible sludge concentrations in solution (Leishear, et al. [2]), and techniques to use those probes were improved.

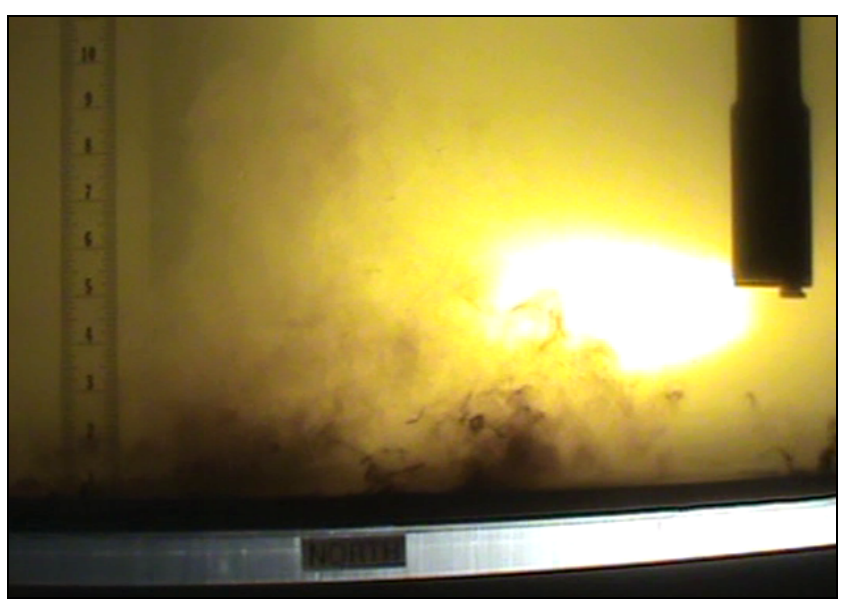

Figure 13: Minimal Sludge Disturbance

For the pilot scale tank with or without coils, the limiting $U o D$ required for minimal sludge disturbance was different (Leishear, et al. [2]), but CFD modeling (Lee and Armstrong [13]) showed that the velocity required to disturb sludge was comparable (0.34 feet/second). Numerous CFD models were performed for this research, and results for velocities at the top of a sludge layer are shown in Fig. 14 and Fig. 15. These two figures were selected to have the same $U o D$ values required to minimally disturb sludge. 


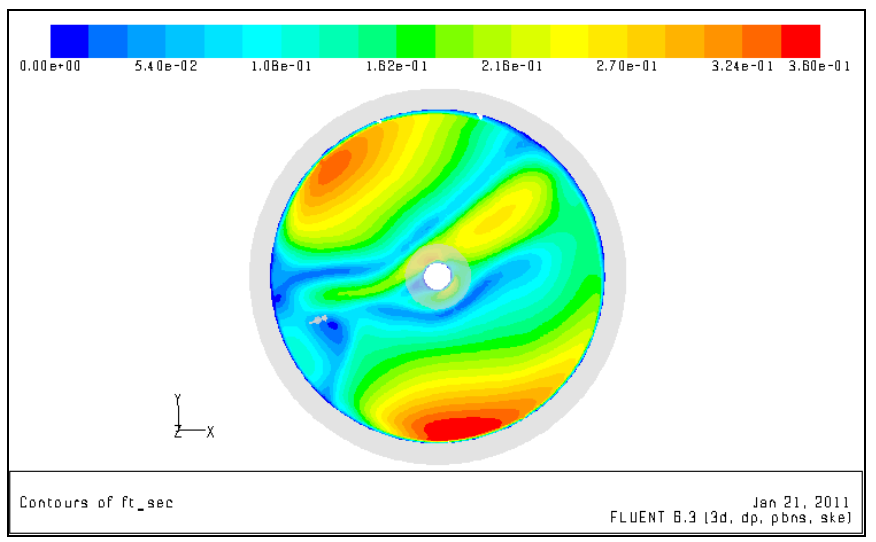

Figure 14: Velocities at the Sludge Layer for a Pilot Scale, Slip Plane Model, UoD $=0.58 \mathrm{feet}^{2} /$ second

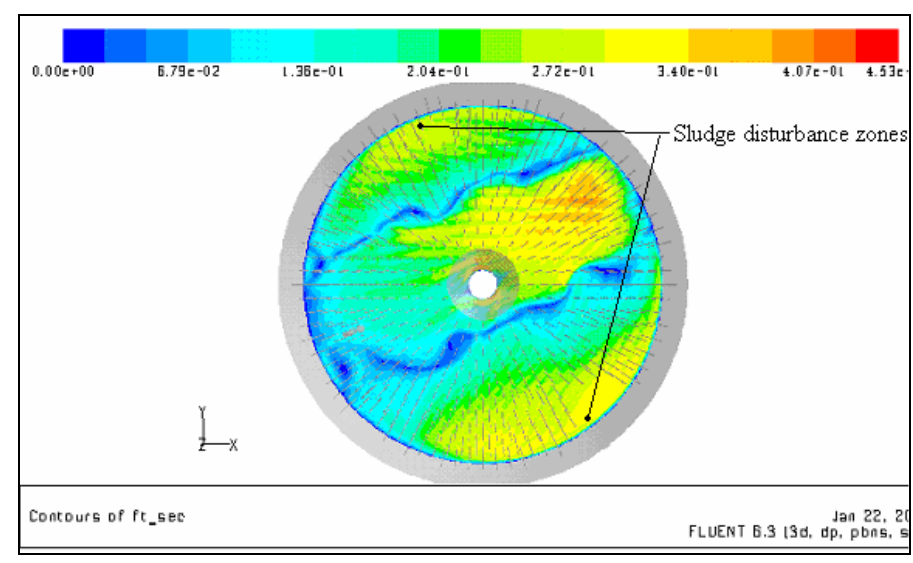

\section{Figure 15: Velocities at the Sludge Layer for the Pilot Scale, Slip Plane Model, UoD $=0.70$ feet ${ }^{2} /$ second}

Also, CFD models showed that coils affected blending times similarly at both pilot and full scale in the range of interest where CFD and experimental results are consistent (Fig. 16). Specifically, CFD results for Phase 1 tee nozzles were compared. Comparison at $U o D=0.81$, feet ${ }^{2} /$ second $^{2}$ yields 7.20 and 10.73 minutes for no coils and coils respectively, and comparison at $U o D=10.85^{*} 0.81=8.8$ feet ${ }^{2} /$ second: 64.0 and 99.5 minutes. Then for pilot scale, $10.73 / 7.2=1.48$; and for full scale, $99.5 / 64=1.55$. Accordingly, the blending time ratios are similar for either pilot or full scale. Since the number of CFD models was limited, additional research is recommended to investigate the effects of coils on blending times.

The CFD calculations are discussed in further detail in a supporting report (Lee and Armstrong [13]) for this work, where calculations used standard $\kappa-\varepsilon$ turbulence models. Also, a brief discussion of the grids used for CFD models used in this research is provided in a companion paper (Leishear, et al.
[4]). A more detailed discussion of CFD modeling will also be provided in a subsequent Conference publication in this series of papers to describe this research (in process).

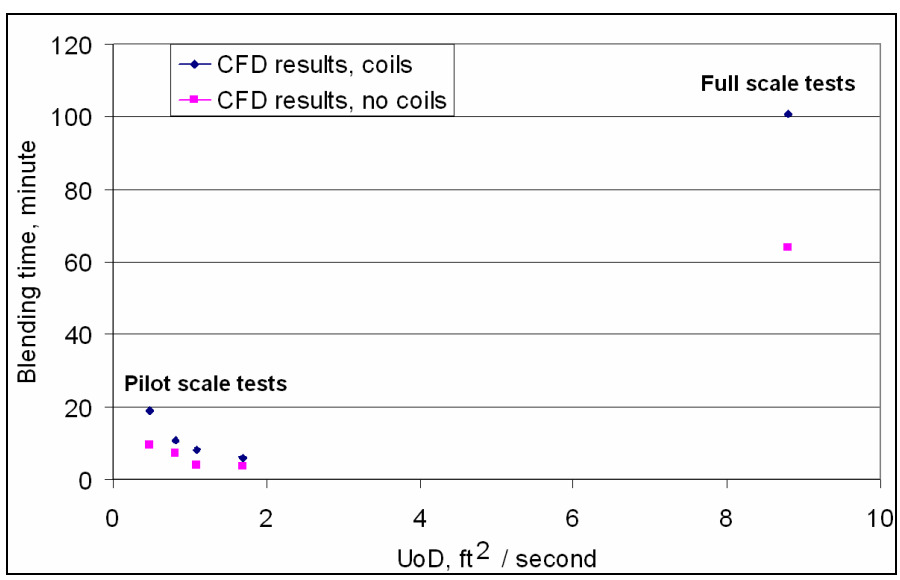

Figure 16: Comparison of CFD Results for a Pilot Scale Tank With and Without Coils Installed, Tee Nozzles

\section{STATISTICAL ANALYSIS AND ENGINEERING EVALUATION}

Note in Figs. 17 and 18 that the CFD model results are in the range of experimental blending times. However, the large variance in experimental data for a tank required consideration. To do so, statistical analyses and engineering evaluations were performed to evaluate the variability of blending times, which were then used to establish a correction factor to be used with CFD models (Leishear, et al. [4]. Statistical analysis was performed for the data shown in Fig. 21 , and the worst case blending time uncertainty was determined to be $\pm 164 \%$ at pilot scale. A correction factor of 2.64 could then be recommended for application to pilot scale CFD results. However, what is the correction factor at full scale? Certainly the $164 \%$ value is applicable, but velocity was also shown to have an uncertainty from a combination of pilot scale and full scale tests. This uncertainty was $\pm 56 \%$ throughout a range of velocities typical of pilot and full scale pump performance. Although the velocity uncertainty may, or may not, be applicable to full scale blending, a conservative approach is to apply that uncertainty as well, since full scale blending data is unavailable for a tank with coils installed. That is, for pilot and full-scale pump operations, pump flow rates and resultant velocities are proportional to blending times, and velocities vary by $56 \%$, then blending times are also assumed to vary by $56 \%$. Then the variability of blending times can be determined by multiplying to obtain a CFD blending time correction factor, $C_{f}$, where $C_{f}=1$ plus the uncertainty equals

$$
C_{f}=1+\sqrt{0.56^{2}+1.64^{2}}=2.73
$$


Similarly, for a tank without coils, the correction factor equals

$$
C_{f}=1+\sqrt{0.56^{2}+0.94^{2}}=2.10
$$

Derivations of these correction factors are discussed in a companion paper (Leishear, et al. [4]).

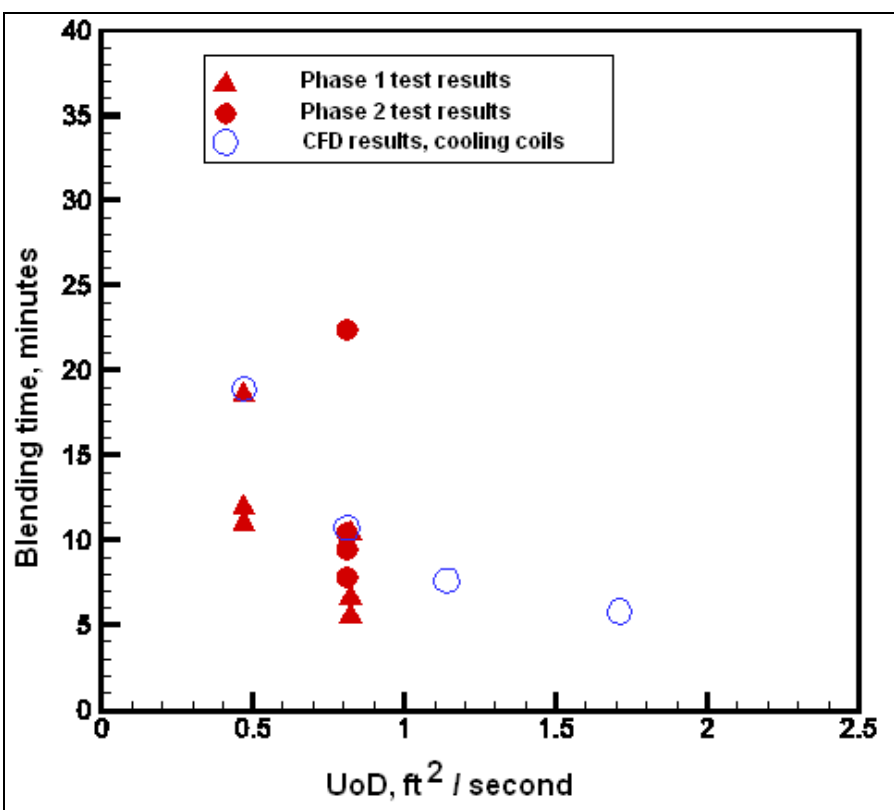

Figure 17: Comparison of CFD Results to Experiments for a Tank With Coils Installed

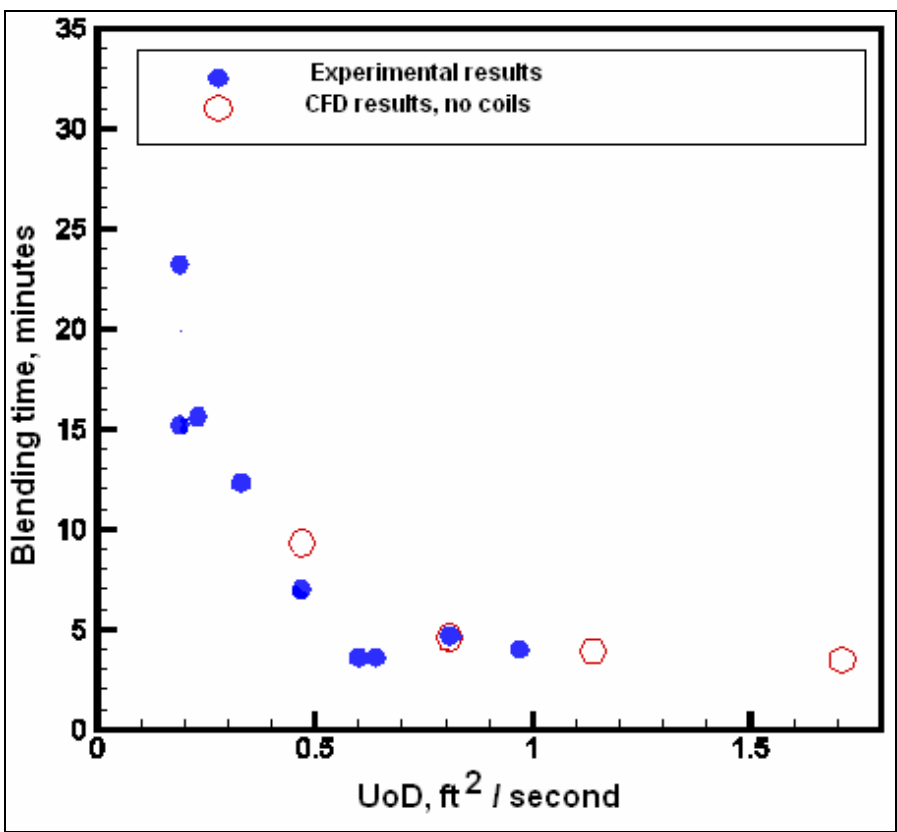

Figure 18: Comparison of CFD Results to Experiments for a Tank Without Coils Installed

\section{SCALE-UP CONSIDERATIONS}

An example using a 2.73 correction factor is in order to clarify its use. Calculations were performed to assess the application of the correction factor to CFD models. Two examples are provided for a tank with coils and horizontal nozzles at $U o D=7.6 \mathrm{feet}^{2} / \mathrm{second}$ (pilot scale $U o D=0.70$ feet ${ }^{2} /$ second),

Example 1: From Phase 1 research (Leishear, et al. [1 and 3]), the estimated blending time was conservatively estimated at $\mathbf{6 . 8 0}$ hours. This estimate was calculated using Equation 2, based on a $95 \%$ confidence level and the upper, limiting values of blending times measured in Phase 1 research. Coil effects were approximated.

Example 2: CFD predicts 140 minutes (Case 14, S. Lee and Armstrong [13]). Corrected, the maximum blending time equals $2.73 \cdot 140 \mathrm{~min} \cdot(1$ hour $/ 60 \mathrm{~min})=\mathbf{6 . 3 7}$ hours .

This estimate of the blending time was based on all Phase 2 average experimental blending time data and a $95 \%$ confidence level to find the maximum blending time.

For these examples, CFD predicted blending times were within $10 \%$ of calculated blending times.

Examples 1 and 2 provide strong inductive evidence of scale-up techniques. Similar test conditions were used in two sets of tests to compare Phase 1 and Phase 2 blending time calculation techniques. Example 1 used Phase 1 test results, and empirical equations, while Example 2 used Phase 2 results and CFD models. Two independent sets of data supported by two independent calculation techniques yielded similar results. The scale-up techniques worked well, but full scale blending tests are recommended for validation. This example is the crux for scale-up resulting from this research, since two completely different techniques yielded similar solutions.

\section{STRATIFICATION}

The method of adding fluids to the tank affects blending. For these tanks, salt solutions were dropped into the tank from above the liquid level through a three inch diameter transfer pipe. When heavier, or similar density, fluids were added to the tank, blending was completed by the mixing caused by the fluid addition. However, when lighter fluids were added to heavier fluids, stratification significantly affected the blend time. For a much higher density salt solution of 2.33 centipoise and $1.317 \mathrm{grams} / \mathrm{milliliter}$, the effects of stratification are shown in Fig. 19 in the form of stratification layer. An interface layer formed between the partially mixed water and salt solution above the interface and the unmixed salt solution below the interface. Over time, this interface lowered as shown in Fig. 20. The blending time to lower the interface layer and 
completely blend the tank contents was 6.73 hours instead of an expected blending time of 8.4 minutes. The full scale blending time may scale up from several days to a week, or more. Even so, only a single test was performed for adding low to high density fluids and the effects of density and viscosity on blending were not evaluated for cases where the fluids had nearly equal densities. Additional research is recommended.

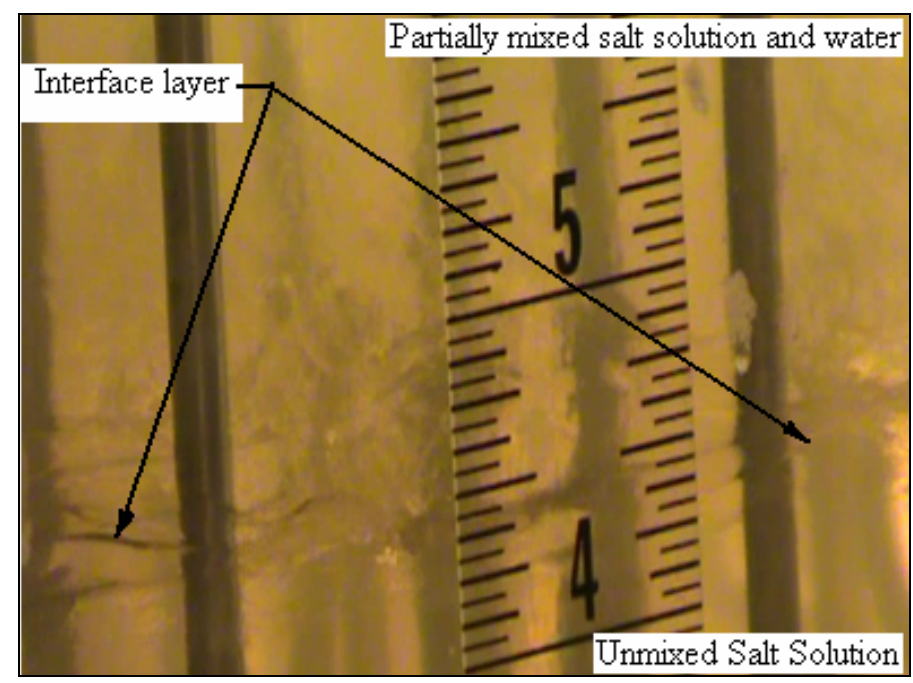

Figure 19: Interface Between Salt Solution Layers, Transfer of Water into a Salt Solution

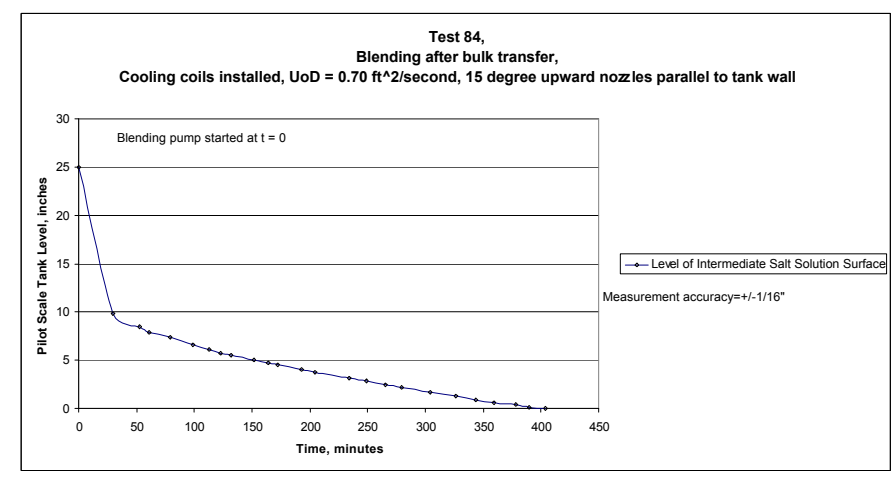

\section{Figure 20: Interface Layer, Level Changes During Blending of a Stratified Salt Solution, Transfer of Water to Salt Solution}

\section{FACILITY OBSERVATIONS \\ RECOMMENDATIONS}

AND

From this research, several recommendations were provided for facility operations, along with supporting observations applicable to those recommendations.

1. The design parameter for opposing, dual nozzle, blending pumps was defined by $U o D$, where $U o$ is the discharge velocity for each pump nozzle, and $D$ is the nozzle diameter.

2. For a specified waste tank design with cooling coils and a center, roof support column, pump design recommendations were:

a. For adequate blending, $\quad U_{0} D>5.10$ feet $^{2} /$ second, and

b. To prevent sludge disturbance, $U_{0} D<6.10$ feet ${ }^{2} /$ second

3. For a waste tank design with a center column but without cooling coils, pump design recommendations were:

a. For adequate blending,

$U_{0} D>3.58$ feet $^{2} /$ second, and

b. To prevent sludge disturbance, $U_{0} D<4.85$ feet $^{2} /$ second.

4. Within the $U o D$ ranges given above, a single, nonrotating blending pump can blend salt contents for a waste tank design.

5. The term "similar fluid" requires definition, where similar solutions have similar viscosity and density. Quantifying material property differences to quantitatively define "similar" solutions was not performed during this research.

6. The maximum predicted full scale blending times were recommended as follows for a design without cooling coils, a center roof support column, and similar density fluids.

a. At $U o D=4.85 \mathrm{feet}^{2} /$ second the recommended blending time is 3.05 hours.

b. At $U o D=3.58$ feet ${ }^{2} /$ second the recommended blending time is 4.13 hours.

7. The predicted full scale blending times were recommended as follows for a design with cooling coils, a center roof support column, and similar density fluids.

a. At $U o D=6.10 \mathrm{feet}^{2} / \mathrm{second}$ the recommended blending time is 7.25 hours.

b. At $U o D=5.10 \mathrm{feet}^{2} /$ second the recommended blending time is 8.66 hours.

8. When large quantities of salt solutions which are denser than, or of similar density to the tank contents, are added to a tank, blending may possibly be completed by the transfer process without operating the blending pump. Recommended blending times ensure that the tank contents are fully blended, since the quantitative effects of transferring denser fluids into less dense fluids at full scale were not further investigated. Further investigation is recommended, since only one test was performed for this condition.

9. When less dense solutions are added to denser solutions in a tank, blending times may increase to several days or longer, depending on the differences in density. The effects of batch salt concentrations on blending times during bulk transfers at full scale were 
not further evaluated for the addition of less dense salt solutions to denser salt solutions. Further investigation is recommended, since only one test was performed for this condition, which added water to a salt solution with a density of 1.317 grams/milliliter.

10. Blending is a random, chaotic process, and the last point in the tank to reach the $95 \%$ blending criterion varied from test to test for similar conditions.

11. A single probe can be used to measure blending times with $95 \%$ confidence, but a correction factor of 4 is recommended to be applied to a measured blending time in a tank with coils installed. For a tank without coils, the recommended correction factor is 2.10 .

\section{CONCLUSIONS}

Extensive SDI research was a significant step toward bench marking and applying CFD modeling to blending. This research showed that CFD models not only agreed with experiment, but demonstrated that the large random variance in experimental data accounted for misunderstood discrepancies between CFD models and experiments. Having documented this finding, SRNL provided correction factors to be used with CFD models to statistically bound full scale CFD results. Specifically, SRNL demonstrated how to effectively apply CFD results to salt batch mixing in full scale waste tanks through the use of experimental testing. In general, CFD modeling techniques had un-quantified errors prior to development of experimental correction factors determined during this research, which provided a technique to use CFD models for salt batch mixing pump operations. This scientific advance in mixing technology resulted in multi-million dollar cost savings to SRR, where techniques were improved for both experimentation and analysis to complete this research. In short, the developed techniques qualified the use of CFD models to analyze the blending of miscible fluids in many tank designs by applying the appropriate CFD correction factor. Research also observed stratification effects in some cases when blending different viscosity fluids that may significantly increase the blending time and require further investigation.

\section{ACKNOWLEDGMENTS}

This research was performed per SRR direction of Keith Harp, Program Manager, Bill Van Pelt, Project Engineering Manager, Ken Parkinson, Lead Engineer, and Bob Ervin, Engineer, who each provided technical requirements and project leadership for this research.

\section{REFERENCES}

[1] Leishear, R. A., Fowley, M. D., Poirier, M. R., Steeper, T. J., 2010, "Cooling Coil Effects On Blending in a Pilot Scale Tank”, AIChE Annual Conference, New York, New York.
[2] Leishear, R. A., Fowley, M. D., Poirier, M. R., Lee, S. Y., Parkinson, K. S., and Steeper, T. J., 2011, "Incipient Sludge Mixing in Nuclear Waste Tanks During Salt Blending “, Waste Management 2011 Conference, Phoenix, AZ, Paper No. 11086.

[3] Leishear, R. A., Poirier, M. R., and Fowley, M. D., "SDI Blend and Feed Blending Pump Design Phase 2", Savannah River National Laboratory, SRNL-STI-2010-00151, May 2011.

[4] Leishear, R. A., Fowley, M. D., Poirier, M. R., Lee, S. Y., and Steeper, T. J., 2011, "Blending Time and Velocity Variations During Blending in a Tank Using Dual Opposing Jets", IMECE2011-62116, International Mechanical Engineers Congress and Exposition, American Society of Mechanical Engineers, New York, New York.

[5] Grenville, R., Tilton, J., 1996, “A New Theory Improves the Correlation of Blend Time Data from Turbulent Jet Mixed Vessels", Trans. Inst. of Chem. Eng., Vol. 74, pp. 390-396.

[6] Grenville, R., Tilton, J., 1997, "Turbulence or Flow as a Predictor of Blend Time in Turbulent Jet Mixed Vessels", Proceedings of the North European Conference on Mixing, pp. 67-74.

[7] Paul, E. L., Atieno-Oberg, V. A., Kresta, S. M., Eds., 2004, "Handbook of Industrial Mixing", Brown, D. A. R., Jones, P. N., Middleton, J. C., "Experimental Methods", Hoboken, John Wiley and Sons, New Jersey, pp. $164-174$.

[8] R. A. Dimenna, S. Y. Lee, and D. A. Tamburello, 2011, "Advanced Mixing Models", SRNL-STI-2011-00026, Savannah River National Laboratory.

[9] Patwardhan, A. W., 2002, "CFD Modeling of Jet Mixed Tanks”, Chemical Engineering Science, 57, pp. 1307-1318.

[10] Rahimi and Parvareh, 2005, "Experimental and CFD Investigation on Mixing by a Jet in a Semi-Industrial Stirred Tank", Chemical Engineering Science, Pergamon Press, Miamisburg, Ohio, 115, pp. 85-92.

[11] Rautzen, R. R. Corpstein, and D. S. Dickey, 1976, "How to Use Scale-Up Methods for Turbine Agitators", Chemical Engineering Journal, Elsevier, Miamisburg, Ohio.

[12] Davies, J. T., 1972, “Turbulence Phenomena”, Academic Press, New York, New York.

[13] Lee, S., Armstrong, B., "SDI, CFD Modeling Analysis", Savannah River National Laboratory, SRNL-STI-2011-00025. 
ANNEX A: TEST RESULTS

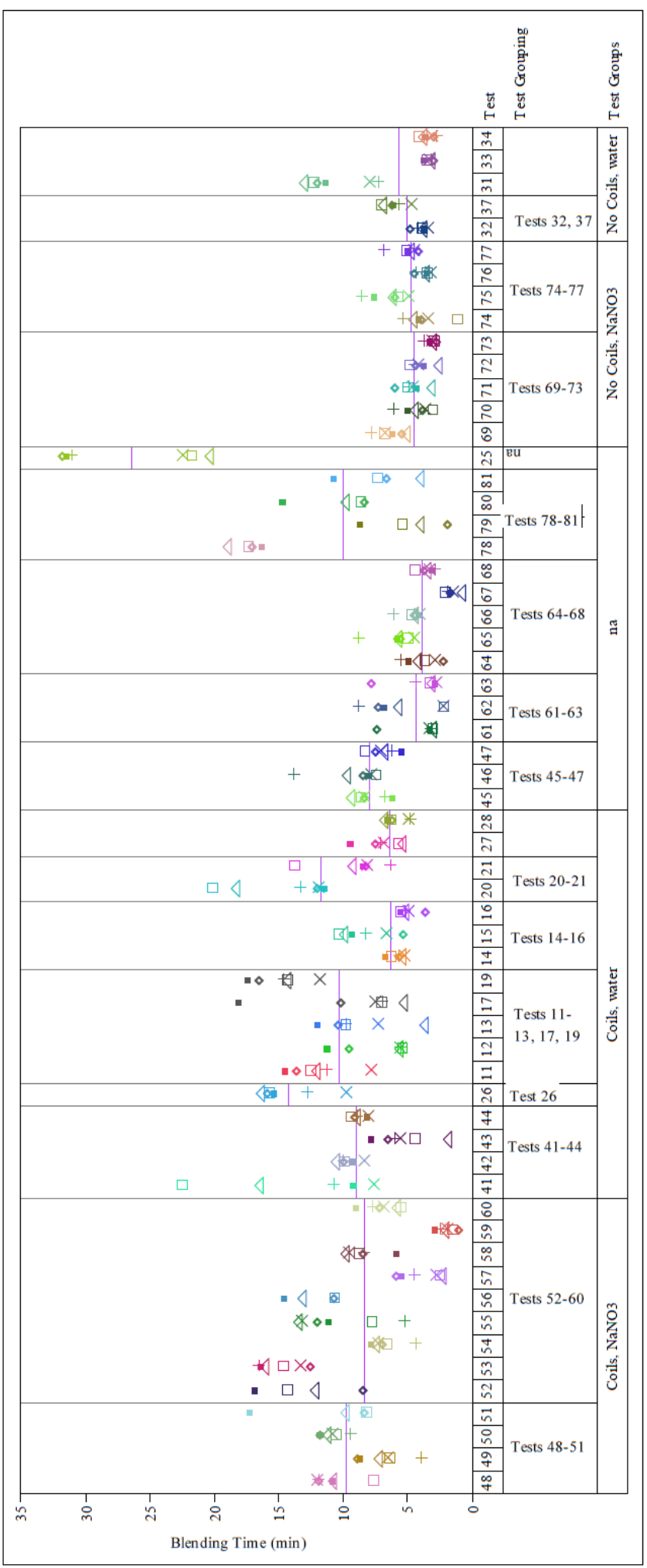

Figure 21: Summary of Blending Test Results (T. Edwards) 
Table1: Phase 1, Tabulated Blending Test Results

\begin{tabular}{|c|c|c|c|c|c|c|c|c|c|c|c|c|c|}
\hline \multicolumn{14}{|c|}{ Phase 1} \\
\hline Test & Test type Nozzle design & $\begin{array}{l}\text { Initial } \\
\text { fluid/ } \\
\text { added } \\
\text { fluid }\end{array}$ & Coils & $\begin{array}{l}\text { Nozzle } \\
\text { position } \\
\text { (deg) }\end{array}$ & $\mathrm{D}$ & $\begin{array}{c}\text { Uo } \\
\text { (ft/s) }\end{array}$ & $\begin{array}{c}\mathrm{UoD} \\
\left(\mathrm{tan}^{n} 2 / \mathrm{s}\right)\end{array}$ & Probe & $\begin{array}{c}\text { Probe } \\
2\end{array}$ & $\begin{array}{c}\text { Probe } \\
3\end{array}$ & $\begin{array}{l}\text { Probe } \\
4\end{array}$ & $\begin{array}{c}\text { Probe } \\
5\end{array}$ & Probe \\
\hline & 1 Blending, dye, Quad, Tee & $\begin{array}{l}\text { Water, } \\
\text { Dye }\end{array}$ & Y & 0 & 0.334 & 7.90 & 0.22 & & & & & & \\
\hline & 2 Blending, dye, Quad, Tee & $\begin{array}{l}\text { Water, } \\
\text { Dye }\end{array}$ & Y & 90 & 0.334 & 7.97 & 0.22 & & & & & & \\
\hline & 3 Blending, dye, Quad, Tee & $\begin{array}{l}\text { Water, } \\
\text { Dye }\end{array}$ & Y & 45 & 0.334 & 7.70 & 0.21 & & & & & & \\
\hline & 4 Diffusion, dye, Tee & $\begin{array}{l}\text { Water, } \\
\text { Dye }\end{array}$ & Y & N/A & N/A & 0 & 0 & & & & & & \\
\hline & 5 Diffusion, base, Tee & $\begin{array}{l}\text { Water, } \\
\text { Base }\end{array}$ & Y & N/A & N/A & 0 & 0 & & & & & & \\
\hline & 6 Diffusion, acid, Tee & $\begin{array}{l}\text { Water, } \\
\text { Acid }\end{array}$ & N & N/A & N/A & 0 & 0 & & & & & & \\
\hline & 7 Blending, Quad, Tee & $\begin{array}{l}\text { Water, } \\
\text { Base }\end{array}$ & Y & 0 & 0.334 & 7.89 & 0.22 & & & & & & \\
\hline & 8 Blending, Quad, Tee & $\begin{array}{l}\text { Water, } \\
\text { Acid }\end{array}$ & Y & 0 & 0.334 & 7.89 & 0.22 & & & & & & \\
\hline & 9 Blending, Quad, Tee & $\begin{array}{l}\text { Water, } \\
\text { Acid }\end{array}$ & Y & 0 & 0.334 & 7.90 & 0.22 & & & & & & \\
\hline & 10 Blending, Quad, Tee & $\begin{array}{l}\text { Water } \\
\text { Base }\end{array}$ & Y & 0 & 0.334 & 16.93 & 0.47 & & & & & & \\
\hline & 11 Blending, Quad, Tee & $\begin{array}{l}\text { Water, } \\
\text { Acid }\end{array}$ & Y & 0 & 0.334 & 16.94 & 0.47 & 14.41 & 11.29 & 7.77 & 12.5 & 13.61 & $\begin{array}{ll}1 & 12.03 \\
\end{array}$ \\
\hline & 12 Blending, Quad, Tee & $\begin{array}{l}\text { Water. } \\
\text { Acid }\end{array}$ & Y & 0 & 0.334 & 16.94 & 0.47 & 11.16 & 5.55 & 5.5 & 5.4 & 9.53 & 5.59 \\
\hline & 13 Blending, Quad, Tee & $\begin{array}{l}\text { Water, } \\
\text { Base }\end{array}$ & Y & 0 & 0.334 & 16.94 & 0.47 & 11.96 & 9.79 & 7.22 & 9.72 & 10.45 & 5.63 \\
\hline & 14 Blending, Quad, Tee & $\begin{array}{l}\text { Water, } \\
\text { Base }\end{array}$ & Y & 0 & 0.334 & 29.29 & 0.82 & 6.63 & 5.71 & 5.2 & 6.25 & 5.71 & 5.32 \\
\hline & 15 Blending, Quad, Tee & $\begin{array}{l}\text { Water, } \\
\text { Base }\end{array}$ & Y & 0 & 0.334 & 29.38 & 0.82 & 923 & 825 & 6.53 & 10.27 & 533 & 983 \\
\hline & 16 Blending Oud Te & Water, & $Y$ & 0 & 0334 & 2938 & 082 & 545 & 529 & 479 & 552 & 363 & 512 \\
\hline & 10 Diefluning, Quau, ree & Water, & & 0 & 0.004 & 29.00 & & 1007 & & 4.19 & 0.02 & 3.03 & 0.12 \\
\hline & 17 Blending, Short Quad, Tee & Base & Y & 0 & 0.33 & 17.35 & 0.48 & 18.07 & 6.98 & 7.39 & 6.97 & 10.22 & $2 \quad 5.21$ \\
\hline & 18 Blending, Standard, Tee & $\begin{array}{l}\text { Water, } \\
\text { Base }\end{array}$ & Y & 0 & 0.134 & 20.93 & 0.23 & & & & & & \\
\hline & 19 Blending, Standard, Tee & $\begin{array}{l}\text { Water, } \\
\text { Acid }\end{array}$ & Y & 0 & 0.134 & 41.64 & 0.46 & 17.28 & 14.57 & 11.65 & 14.27 & 16.49 & $\begin{array}{ll}9 & 14.27 \\
\end{array}$ \\
\hline & 20 Blending, Quad, Tee & $\begin{array}{l}\text { Water, } \\
\text { Acid, } \\
\text { Dye }\end{array}$ & Y & 90 & 0.334 & 16.94 & 0.47 & 11.35 & 13.31 & 11.86 & 20.04 & 12.03 & 18.22 \\
\hline & 21 Blending, Quad, Tee & $\begin{array}{l}\text { Water, } \\
\text { Base }\end{array}$ & Y & 90 & 0.334 & 16.94 & 0.47 & 8.37 & 6.36 & 8 & 13.72 & 8.22 & 9.28 \\
\hline & 22 Blending, Quad, Tee & $\begin{array}{l}\text { Water, } \\
\text { Acid, }\end{array}$ & Y & 45 & 0.334 & 3.34 & 0.09 & & & & & & \\
\hline & 23 Blending, Quad, Tee & $\begin{array}{l}\text { Water, } \\
\text { Acid }\end{array}$ & Y & 45 & 0.334 & 6.70 & 0.19 & & & & & & \\
\hline & 24 Blending, Quad, Tee & $\begin{array}{l}\text { Water, } \\
\text { Base }\end{array}$ & Y & 45 & 0.334 & 7.89 & 0.22 & & & & & & \\
\hline & 25 Blending, Quad, Tee & $\begin{array}{l}\text { Water, } \\
\text { Acid }\end{array}$ & Y & 45 & 0.334 & 11.90 & 0.33 & 31.38 & 31.05 & 22.33 & 21.64 & 31.8 & 20.31 \\
\hline & 26 Blending Quad Tee & $\begin{array}{l}\text { Water, } \\
\text { Acid, }\end{array}$ & Y & 45 & 0.334 & 16.94 & 047 & 1525 & 1275 & 97 & 1572 & 1587 & $=16.34$ \\
\hline & 27 Blending, Quad, Tee & $\begin{array}{l}\text { Water, } \\
\text { Base }\end{array}$ & Y & 45 & 0.334 & 22.89 & 0.64 & 9.38 & 7.04 & 6.79 & 5.67 & 7.52 & 5.4 \\
\hline & 28 Blending, Quad, Tee & $\begin{array}{l}\text { Water, } \\
\text { Base }\end{array}$ & Y & 45 & 0.334 & 35.71 & 0.99 & 6.46 & 4.8 & 4.83 & 6.19 & 6.19 & 6.8 \\
\hline & 29 Blending, Quad, Tee & $\begin{array}{l}\text { Water, } \\
\text { Acid }\end{array}$ & N & 45 & 0.334 & 6.70 & 0.19 & & & & & & \\
\hline & 30 Blending, Quad, Tee & $\begin{array}{l}\text { Water, } \\
\text { Base }\end{array}$ & N & 45 & 0.334 & 6.70 & 0.19 & & & & & & \\
\hline & 31 Blending, Quad, Tee & $\begin{array}{l}\text { Water. } \\
\text { Acid. }\end{array}$ & N & 45 & 0.334 & 11.85 & 0.33 & 11.26 & 7.25 & 781 & 12.19 & 12.04 & 12.95 \\
\hline & 32 Blending Quad Tee & Water, & $N$ & 45 & 0.334 & 1674 & 047 & 361 & 423 & 336 & 39 & 4.87 & 373 \\
\hline & & $\begin{array}{l}\text { Ease } \\
\text { Water. }\end{array}$ & & & & & & & & & & & \\
\hline & 33 Blending, Quad, Tee & Base & N & 45 & 0.334 & 22.98 & 0.64 & 3.61 & 3.17 & 3.17 & 3.44 & 2.98 & 3.1 \\
\hline & 34 Blending, Quad, Tee & $\begin{array}{l}\text { Water, } \\
\text { Acid }\end{array}$ & N & 45 & 0.334 & 34.99 & 0.97 & 3.55 & 2.78 & 3.02 & 4.07 & 3.02 & 3.72 \\
\hline & 35 Blending, Standard, Tee & $\begin{array}{l}\text { Water, } \\
\text { Acid }\end{array}$ & N & 45 & 0.134 & 9.22 & 0.105 & & & & & & \\
\hline & 36 Blending Standard, Tee & $\begin{array}{l}\text { Water, } \\
\text { Base }\end{array}$ & N & 45 & 0.134 & 20.93 & 0.23 & & & & & & \\
\hline & 37 Blending Standard Tee & $\begin{array}{l}\text { Water, } \\
\text { Acid }\end{array}$ & $\mathrm{N}$ & 45 & 0.134 & 4230 & 047 & 599 & 572 & 465 & 6.97 & 6.24 & 6.9 \\
\hline & 38 Blending, Standard, Tee & $\begin{array}{l}\text { Water, } \\
\text { Base }\end{array}$ & N & 45 & 0.134 & 52.81 & 0.60 & & & & & & \\
\hline
\end{tabular}

Table 2: Phase 2, Tabulated Blending Test Results

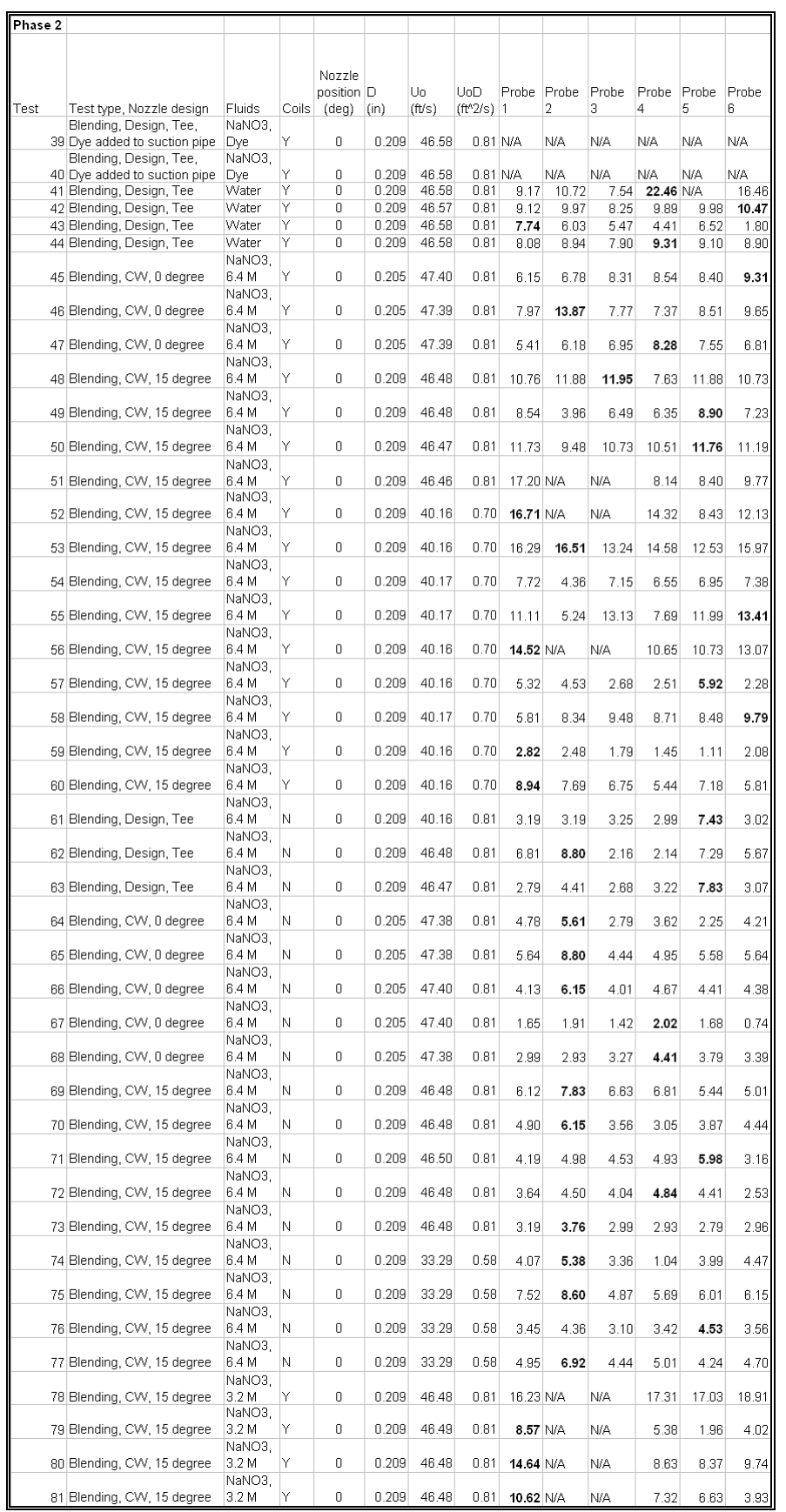

